OPEN ACCESS

Edited by:

Adrian Aguilera,

University of California, Berkeley,

United States

Reviewed by:

Kimberly Tyler,

University of Nebraska-Lincoln,

United States

Michael Musker,

South Australian Health and Medical

Research Institute (SAHMRI), Australia

*Correspondence:

Shalini Lal

shalini.lal@umontreal.ca

Specialty section:

This article was submitted to

Human Factors and Digital Health,

a section of the journal

Frontiers in Digital Health

Received: 23 September 2021

Accepted: 28 October 2021

Published: 24 November 2021

Citation:

Lal S, Halicki-Asakawa A and Fauvelle A (2021) A Scoping Review on Access and Use of Technology in Youth Experiencing Homelessness: Implications for Healthcare.

Front. Digit. Health 3:782145. doi: 10.3389/fdgth.2021.782145

\section{A Scoping Review on Access and Use of Technology in Youth Experiencing Homelessness: Implications for Healthcare}

\author{
Shalini Lal ${ }^{1,2,3 *}$, Amané Halicki-Asakawa ${ }^{2}$ and Amélie Fauvelle ${ }^{1,2}$ \\ ${ }^{1}$ School of Rehabilitation, University of Montreal, Montreal, QC, Canada, ${ }^{2}$ Youth Mental Health and Technology Lab, \\ Innovation and Evaluation Hub, University of Montreal Hospital Research Centre (CRCHUM), Montreal, QC, Canada, \\ ${ }^{3}$ Douglas Mental Health University Institute, Montreal, QC, Canada
}

Introduction: Youth are among the fastest growing subset of the homeless population. Youth experiencing homelessness (YEH) face multiple barriers in accessing health information and health care services. As such, they may best be reached through information and communication technologies (ICTs); however, limited efforts have been made to synthesize literature on this topic. In this paper, we review studies on access and use of ICTs among YEH. We also discuss the implications of the review for healthcare.

Methods: Using scoping review methodology, we searched four databases (Medline, Embase, Psyclnfo, and CINAHL) for studies published between 2005 and 2019, screening 1,927 titles and abstracts.

Results: We identified 19 articles reporting on studies with YEH between the ages of 12-30, the majority of which were published in the USA. On average, more than half of the samples owned smartphones, used social media, and accessed the internet weekly to search for housing, employment, health information, and to communicate with family, peers, and health workers; however, many youths faced barriers to sustaining their access to technology. Benefits of using ICTs were connecting with home-based peers, family, and case workers, which was associated with a reduction in substance use, risky sexual health behaviors, and severity of mental health symptoms. Connecting with negative, street-based social ties was identified as the most common risk factor to using ICTs due to its association with engaging in risky sex behaviors and substance abuse.

Discussion: This review supports the advancement of research and practice on using ICTs to deliver public health information and health services to YEH, while also considering the health-related risks, benefits, and barriers that $\mathrm{YEH}$ face when accessing ICTs.

Keywords: digital equity, telemedicine, telehealth, cellular phone, internet, eMental health, digital health, mhealth 


\section{INTRODUCTION}

Youth homelessness is a serious and complex public health issue. Factors leading to situations of youth homelessness are multifaceted, and involve the interaction of issues such as a lack of affordable housing, economic insecurity, behavioral health, violence at home, lack of positive social supports, and involvement in the child welfare system $(1,2)$. Various definitions have been proposed to describe homelessness. Gaetz et al. (3) define youth experiencing homelessness (YEH) as adolescents and young adults living independently from their caregivers, in unstable or inappropriate housing situations, and lacking the social and material means to successfully transition into adulthood. This definition encompasses youth living on the street, but also the hidden homeless; for example, young people living in hotels and motels, staying with friends, or sleeping in unsafe places, such as cars, tents, or in parks (4-6).

Given the transient nature of the homeless population and heterogeneity in definitions $(7,8)$, it is challenging to provide accurate estimates of the actual number of YEH $(3,9)$. Morton et al. (8) found that in the United States of America (USA), between 700,000 and 3.5 million young adults aged 18-25 experience homelessness each year, with Black youth having a significantly higher risk of homelessness. In Canada, approximately 20 percent (or 30,000-40,000 annually) of individuals experiencing homelessness are young adults aged 1624 , with a similar overrepresentation of youth from marginalized communities (i.e., youth identifying as LGBTQIA2SP+, racialized youth) (2, 9-12). In Canada and the USA, reports show that the rates of homelessness in children and adolescents are outpacing other age groups of the homeless population $(12,13)$.

The health of YEH is of critical concern. Without a stable and safe place to live, they often need to engage in risky activities (e.g., sex trade, selling drugs, carrying a weapon) for basic survival, which may place them at higher risk for developing health problems (12, 14-16). Health issues affecting YEH include, for example, respiratory and dermatology conditions; mood, anxiety, and behavioral disorders; psychosis; attempted suicide; and, substance abuse (11, 12, 14-19). Despite the prevalence of health and social issues among YEH, they are particularly marginalized from the health care system, facing multiple barriers to accessing timely and effective care $(12,16,18,20-23)$. Barriers they face in accessing care include: limited money, difficulties having stable contact information/address/ID, limited knowledge about health services, and negative attitudes and perceptions of healthcare professionals toward the homeless population $(12,16,20,22)$. Consequently, the mortality rates of this population are increased by up to 30 times in comparison to the general public (24-30). Such evidence provides support for the importance of creating interventions and services that are accessible and effective for this population.

Technology-enabled interventions are a promising avenue to address some of the aforementioned barriers and to help

Abbreviations: YEH, Youth experiencing homelessness; ICTs, Information and communication technologies. improve access to health services for YEH. However, prior to developing and delivering health information and services through technology, it is important to know the extent to which YEH use information and communication technologies (ICTs). A previous review of studies published until 2012 concluded that many homeless persons use ICTs and that there is potential for developing technology-delivered interventions aimed at improving health services among this population (31). However, this review included only a few articles that were focused on a younger population (given the nascence of the research at that time) and considering the evolution in technology development and access, the results of such a review warrant updating. Over the past decade, more studies have focused on examining access and use of ICTs among YEH (32), however limited efforts have been made to synthesize this literature. Such knowledge can be useful for informing public health practice (e.g., communicating knowledge to the homeless youth population during public health emergency situations, such as COVID-19) and health care services more broadly.

As such, we conducted a scoping review with the objective of synthesizing knowledge on access and use of ICTs among YEH and to discuss implications for public health care. Our main research questions were: (1) What is known about the rates of access and use of ICTs among YEH?; (2) what are the factors affecting access and use of ICTs among YEH; (3) why do YEH use ICTs (i.e., for what purposes); (4) what are the healthrelated benefits and risks for YEH in using ICTs; and, (5) what implications does the existing research have for future health care research and practice?

The scoping review method was chosen as it provides a systematic, rigorous and transparent approach for mapping a field of interest in terms of the volume, nature and characteristics of existing research (33-35). Scoping review methodology has been increasingly used in the health literature $(34,35)$ and is particularly relevant when reviewers are interested in questions extending beyond intervention effects or in emerging fields of research $(33,36)$. Given that the study of access and use of ICTs among YEH is a relatively new area of research, a scoping review is an important first step in informing future research and practice.

\section{METHOD}

Our review is based on Arksey and O'Malley's (33) five-stage framework for conducting scoping reviews and informed by the Preferred Reporting Items for Systematic reviews and MetaAnalyses extension for Scoping Review (PRISMA-ScR) (36). We first developed a scoping review protocol including a rationale for conducting the review, the main objectives, search strategy, inclusion and exclusion criteria, and methods for screening and data extraction, which was then piloted and discussed by the research team before finalizing. The final protocol was registered retrospectively in Open Science Framework (https:// osf.io) (protocol registration accessible via: https://doi.org/10. 17605/OSF.IO/6NY9B). 


\section{Study Identification and Selection Information Sources and Search Strategy}

A literature database search by subject, title, and abstract was applied using Medline, Embase, PsycInfo, and CINAHL. Three consultations were made with a university-based, paramedical librarian to develop a Medline search strategy, as described in Figure 1, which was then adapted for the other databases. The reference lists of selected articles were also screened to obtain additional articles. An initial search strategy was developed and implemented November 2nd, 2015. Given that we did not find a large number of papers to justify a full-review, we conducted a second search on April 19th, 2016 (including revisions to our keyword strategy), and an updated search on March 6th 2019, each time in consultation with the librarian. All searches involved articles published from 2005 in English and French. This date of publication was chosen given that ICTs have been evolving rapidly over the past decade; thus, literature older than 15 years would not be as pertinent to the current landscape of research and practice in this field. No other limitations were placed.

\section{Selecting Sources of Evidence}

Once the publications were retrieved and duplicates removed using Endnote, the titles and abstracts were screened (the full text was also screened for any articles identified as meeting or potentially meeting the inclusion criteria) to identify documents to be retained for the review based on the following criteria:

\section{Inclusion criteria}

(1) The publication reports on a study regarding accessibility of ICTs for YEH and/or use of ICTs by YEH; (2) the technology discussed in the document is an ICT (e.g., cell phone, social media, email, electronic case management); (3) the publication is written in English; (4) all types of study designs are included (e.g., qualitative, quantitative, mixed methods, descriptive); and (5) the date of the publication is from 2005 onwards.

\section{Exclusion criteria}

Publications were excluded based on the following: (1) the publication reports on a technology that is not included in the definition of ICTs used in this review (e.g., medical technology, diagnosis tools); and (2) the publication focuses on the use of an ICT that is only accessible by a healthcare professional (e.g., electronic medical record).

The inclusion and exclusion criteria were piloted on $10 \%$ of the documents to ensure their clarity and the ability of the research team to identify relevant articles. Revisions to the criteria were then made and applied to the rest of the retrieved titles and abstracts. A2 and A3 each screened a subset of the titles and abstracts, with any unclear articles reviewed at the full text level and discussed with A1, following which a final decision was made regarding study inclusion.

\section{Charting the Data and Reporting Results}

The selected publications were read, annotated, and entered into a Microsoft Excel spreadsheet. The data extraction sheet was piloted by $\mathrm{A} 3$ with two of the included studies, and then revised in consultation with A1. Next, the following information was extracted and classified by two members of the research team (A2, A3): access to technology (including methods of access), use of technology (i.e., frequency of use and purpose), impact on health outcomes, and key conclusions and implications for future research and/or practice. We also extracted basic information, including: authors, publication year, country of publication, study objectives, study design, methods, sample size, and sociodemographic characteristics.

The data extraction of A3 was validated by A2, and the data extraction of A2 was validated by an additional member of the research team. Publications reporting on data from the same study sample were considered a set, and counted as one study in the PRISMA diagram. In terms of summarizing the data, where applicable, simple weighted averages were calculated by A2 in consultation with a statistician based on study sample size for data pertaining to rates of access and use of ICTs, and for sociodemographic information (i.e., studies that did not report on a category of information were not included in the weighted average calculations). The qualitative data (e.g., reasons for using ICTs, methods of access, risks and benefits to ICT use) was coded by A2 and managed using Microsoft Excel and validated by an additional member of the research team. We did not conduct a critical appraisal of the included studies given that this is not typically an objective of conducting a scoping review $(33,35,36)$ and the large research design heterogeneity of the studies reviewed.

\section{RESULTS}

We identified 19 relevant peer-reviewed articles reporting on access and use of ICTs in YEH, though six of these were paired together and considered one set as they reported on data from the same study sample, resulting in a dataset of 16 study samples (see Figure 2 for the adapted PRISMA flow diagram and details on numbers of items screened and excluded, including reasons for exclusions). The 19 articles were published between 2010 and 2018, with 17 from the USA, one from Canada, and one from Australia. Appendix Table 1 (Supplementary Material) provides a summary of the objectives and results of each of the studies included in the review. The total sample was comprised of 3,123 participants (sample sizes ranged from 20 to 829; the majority under 200), aged between 12 and 30 years old, 2,856 (91.5\%) of which were YEH living in a variety of housing situations (e.g., shelters, living on the street, temporary housing, etc.). The YEH group comprised of 1,876 (65.9\%) males, 898 (31.5\%) females, and $44(1.5 \%)$ transgendered individuals, within the 18 papers in which sex was reported. Within the 16 papers that reported on ethnicity, the majority of YEH $(n=916 ; 32.6 \%)$ were Black/African American, approximately a third were White $(n=859 ; 30.6 \%)$, and the rest were Hispanic/Latinx $(n=422$; $15 \%)$, or mixed race $(n=367 ; 13.1 \%)$. See Table 1 for additional sociodemographic information.

\section{Rates of Access and Use}

Four studies reported on the rates that $\mathrm{YEH}$ access and use mobile phones; on average, $62.6 \%$ owned a mobile phone $(32,37-$ $39)$. Based on two studies, an average of $68.8 \%$ specifically owned 


\begin{tabular}{|c|c|c|}
\hline 1. exp Internet/ & 20. exp Biosensing Techniques/ & $\begin{array}{l}24.1 \text { or } 2 \text { or } 3 \text { or } 4 \text { or } 5 \text { or } 6 \\
\text { or } 7 \text { or } 8 \text { or } 9 \text { or } 10 \text { or } 11 \text { or }\end{array}$ \\
\hline 2. exp Cell Phone/ & 21. exp Video Recording/ & $\begin{array}{l}12 \text { or } 13 \text { or } 14 \text { or } 15 \text { or } 16 \text { or } \\
17 \text { or } 18 \text { or } 19 \text { or } 20 \text { or } 21 \text { or }\end{array}$ \\
\hline 3. exp Smartphone/ & 22. exp Online Systems/ & 22 or 23 \\
\hline $\begin{array}{l}\text { 4. exp Computers/ or exp } \\
\text { Computers, Handheld/ }\end{array}$ & $\begin{array}{l}\text { 23. (internet or "cell phone*" or } \\
\text { cellphone* or "mobile phone*" }\end{array}$ & 25. exp Homeless Persons/ \\
\hline 5. exp Mobile Applications/ & $\begin{array}{l}\text { or "smart phone*" or } \\
\text { smartphone* or "mobile app*" } \\
\text { or computer* or "social media*" }\end{array}$ & $\begin{array}{l}\text { 26. (homeless* or street* } \\
\text { youth* or street* adolescen* } \\
\text { or street* teen* or runaway }\end{array}$ \\
\hline 6. exp Telemedicine/ & $\begin{array}{l}\text { or Facebook or "text messag*" } \\
\text { or "electronic messag*" or }\end{array}$ & $\begin{array}{l}\text { youth* or runaway } \\
\text { adolescen* or runaway teen* }\end{array}$ \\
\hline 7. exp Social Media/ & $\begin{array}{l}\text { "electronic mail*" or email* or } \\
\text { "e-mail*" or "social network*" }\end{array}$ & $\begin{array}{l}\text { or street* living youth* or } \\
\text { street* living adolescen* or }\end{array}$ \\
\hline 8. exp Technology/ & $\begin{array}{l}\text { or technolog* or "electronic } \\
\text { case* management" or web or }\end{array}$ & $\begin{array}{l}\text { street* living } \\
\text { teen*).ab,kf,kw,ti. }\end{array}$ \\
\hline 9. exp Medical Records & website* or "virtual reality" or & \\
\hline Systems, Computerized/ & $\begin{array}{l}\text { "mobile device*" or video* or } \\
\text { portal* or chatbot* or robot* or }\end{array}$ & 27.25 or 26 \\
\hline 10. exp Electronic Mail/ & $\begin{array}{l}\text { "wearable device*" or sensor or } \\
\text { sensors or biosensoror or "bio- }\end{array}$ & 28.24 and 27 \\
\hline 11. exp Social Networking/ & $\begin{array}{l}\text { sensor" or biosensors or "bio- } \\
\text { sensors" or smartwatch* or }\end{array}$ & $\begin{array}{l}\text { 29. limit } 28 \text { to (yr="2005 - } \\
\text { Current" and (english or }\end{array}$ \\
\hline 12. exp User-Computer & "smart watch*" or ereferr* or "e- & french)) \\
\hline Interface/ & $\begin{array}{l}\text { referr*" or chat or online or } \\
\text { "instant messag*" or cyber* or }\end{array}$ & \\
\hline 13. exp Web Browser/ & $\begin{array}{l}\text { avatar* or platform* or } \\
\text { telehealth* or "tele-health*" or }\end{array}$ & \\
\hline 14. exp Virtual Reality & telepsychiatry or "tele- & \\
\hline Exposure Therapy/ & $\begin{array}{l}\text { psychiatry" or telepsychology or } \\
\text { "tele-psychology" or "telemental }\end{array}$ & \\
\hline 15. exp Virtual Reality/ & $\begin{array}{l}\text { health*" or "tele-mental health*" } \\
\text { or teletherapy or "tele-therapy" }\end{array}$ & \\
\hline 16. exp Computer Simulation/ & $\begin{array}{l}\text { or telemedicine or "tele- } \\
\text { medicine" or telerehabilitation or }\end{array}$ & \\
\hline 17. exp video-audio media/ & $\begin{array}{l}\text { "tele-rehabilitation" or "emental } \\
\text { health*" or "e-mental health*" or }\end{array}$ & \\
\hline 18. exp Robotics/ & $\begin{array}{l}\text { ehealth* or "e-health*" or } \\
\text { mhealth* or "m- }\end{array}$ & \\
\hline $\begin{array}{l}\text { 19. exp Wearable Electronic } \\
\text { Devices/ }\end{array}$ & health*").ab,kf,kw,ti. & \\
\hline
\end{tabular}

FIGURE 1 | 2019 search strategy launched in Medline. * refers to the inclusion of all forms of the word (e.g., plural form).

a smartphone $(32,38)$. The range of mobile phone ownership was wide (46.7-100\%); for example, one study found that $78 \%$ of those in their quantitative analysis $(n=41)$ and $90 \%$ of those in their qualitative analysis $(n=52)$ owned a mobile phone (38), whereas another study found that their entire sample $(n=22)$ owned a mobile phone (37).

Eight studies reported on the rates that $\mathrm{YEH}$ access and use the internet; on average, $38.2 \%$ used the internet at least once daily, with a range of $28-86.5 \%$ (32, 4046). Based on four studies, an average of $55.1 \%$ of $\mathrm{YEH}$ accessed the internet at least once a week, with a range of $45-93 \%(41,43,44,46)$. Two of the studies reported that a significant majority of their sample used the internet regularly, but did not report on the actual frequency of access $(32,42)$.
Finally, 13 studies found that $\mathrm{YEH}$ access and use social media in some capacity $(32,37,40,43-52)$. Based on seven studies, an average of $77.1 \%$ used social media, with a range of $57-90.7 \%(32,45-49,52)$. Two of the studies reported on the frequency of YEH's social media use, with an average of $36.0 \%$ reporting daily social media use, and $26.6 \%$ reporting weekly use $(47,52)$.

\section{How Youth Experiencing Homelessness Access ICTs}

Ten studies described how YEH accessed ICTs (32, 38-40, 42-46, 49). Cell phones were sometimes obtained as a gift, purchased with personal money, or with money obtained from panhandling, a job, or federal benefits $(32,38,39)$. The internet 


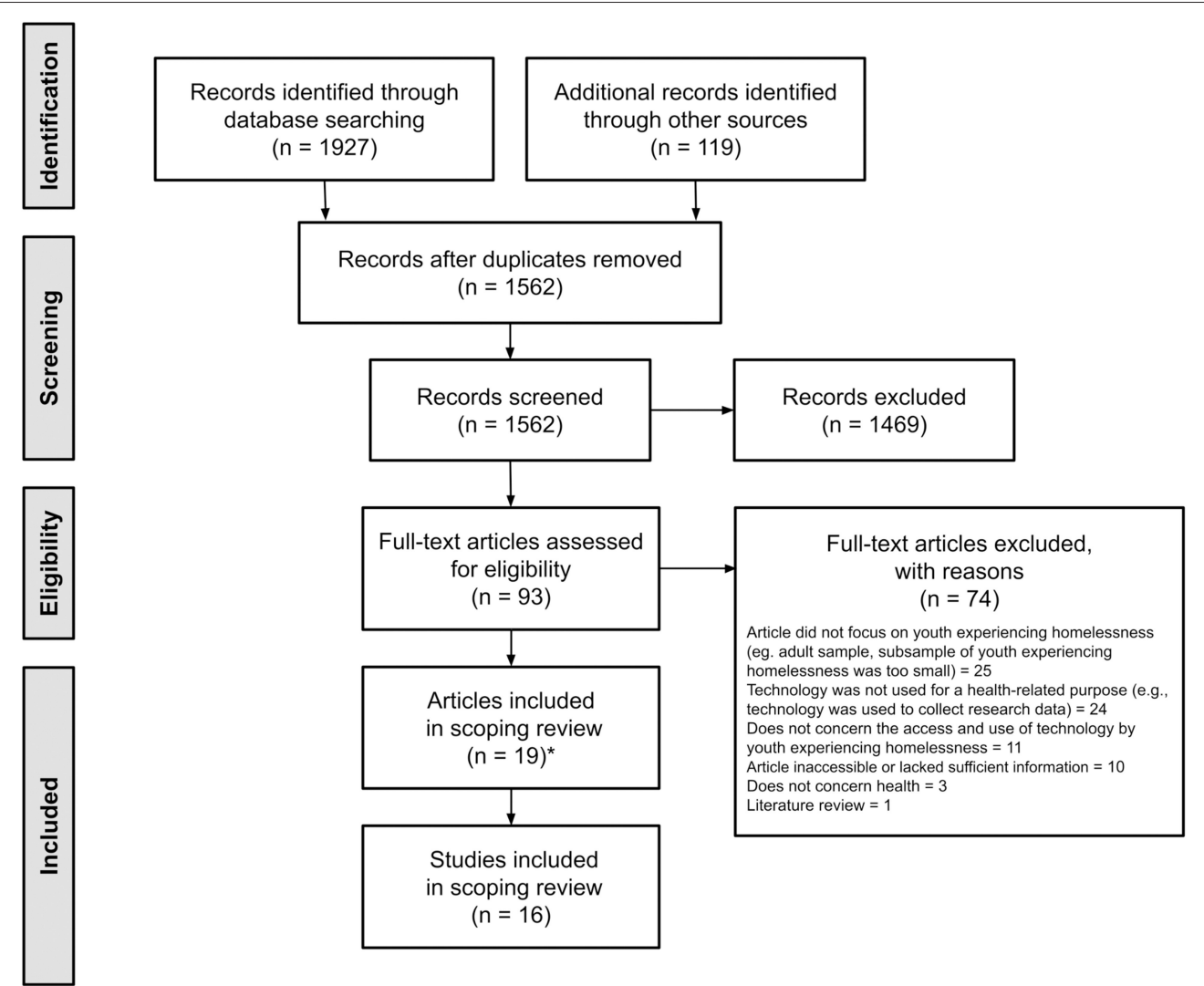

FIGURE 2 | Preferred Reporting Items for Systematic reviews and Meta-Analyses (PRISMA) diagram. *Six of the articles were grouped together into three pairs, as each set reported on data collected from the same sample.

was commonly accessed via a friend/family member's or publiclyavailable device; through public libraries and Wi-Fi; and through youth service community agencies, Internet cafes, schools, and workplaces $(42-46,49)$.

\section{Reasons for Using ICTs}

Eighteen studies addressed the reasons for YEH's use of ICTs (32, 37-53). Reasons for use most frequently cited were to navigate social networking sites $(n=13)$, to communicate with peers $(n=11)$ and family members $(n=9)$, to conduct job-related activities $(n=9)$, for communication generally (e.g., checking email; $n=8$ ), and to seek health services $(n=5)$ and health-related information $(n=5)$. Table 2 provides additional details on the reasons for which YEH used ICTs.

\section{Factors Affecting Access to ICTs}

Eleven studies identified factors that affected YEH's access to and use of ICTs $(32,37-42,45,46,49,54)$. The most cited factor was the actual living situation of the youth $(n=6)$, with youth experiencing homelessness or street-based living situations reporting less access to ICTs than youth who were able to find housing more consistently $(32,39,41,45,46,49)$. For example, one study found that participants residing in a house or an apartment were more likely to engage in regular use of social media (90.6\%) than those living on the streets (55.6\%) (32). Compared to when they were housed, YEH's internet behaviors became more goal-oriented, with less time spent on leisurely activities or entertainment (46).

Other factors affecting ICT access included the youth's financial situation and the availability of public devices. Unstable financial situations often led to phone deactivation due to missed payments, to sharing devices with a friend, to having the phone stolen, and difficulties in maintaining the device's functionality (e.g., charging the phone) $(37,38,54)$. Some participants reported challenges accessing ICTs through public institutions, such as specific hours of operation, long wait times, downloading or printing difficulties, and website restrictions (42).

Despite the barriers they faced in accessing technology, one study found that youth reported comfort in using ICTs (70\% selfassessed their computer abilities as better than average, and $85 \%$ reported being able to use a computer), due to previous family and school experiences. In addition, youth used ICTs for a diverse range of activities, suggesting a relatively high level of digital literacy (42).

\section{Risks and Benefits of Using ICTs With Youth Experiencing Homelessness}

Eleven studies established a link between the use of ICTs by YEH and to certain risks and benefits $(38-40,42,44,47,49-53)$. The 
TABLE 1 | Participant sociodemographics.

\begin{tabular}{lcc}
\hline & N & $\%$ \\
\hline Total sample & 3,123 & $100.0 \%$ \\
YEH & 2,856 & $91.5 \%$ \\
YEH sample from studies that examined ethnicity & 2,808 & $98.3 \%$ \\
Black/African American & 916 & $32.6 \%$ \\
White & 859 & $30.6 \%$ \\
Hispanic/Latinx & 422 & $15.0 \%$ \\
Mixed race & 367 & $13.1 \%$ \\
Other & 345 & $12.3 \%$ \\
Unknown/missing information & 2 & $0.1 \%$ \\
YEH sample from studies that examined sex & 2,847 & $99.7 \%$ \\
Male & 1,876 & $65.9 \%$ \\
Female & 898 & $31.5 \%$ \\
Transgender & 44 & $1.5 \%$ \\
Unknown/missing information & 29 & $1.0 \%$ \\
YEH sample from studies that examined sexuality & 2,189 & $76.6 \%$ \\
Heterosexual & 1,628 & $74.4 \%$ \\
LGBTQIA2SP+ & 558 & $25.5 \%$ \\
Unknown/missing information & 3 & $0.1 \%$ \\
\hline
\end{tabular}

YEH, Youth experiencing homelessness.

most common benefit was the ability to connect with positive social ties, such as home-based peers, family members and case workers, which was associated with a reduction in substance use, risky sexual health behaviors, and severity of mental health symptoms (40, 44, 47, 50, 52).

However, connecting with negative, street-based social ties was identified as the most common risk factor to using ICTs due to its association with an increased likelihood of engaging in risky sex behaviors (e.g., exchange sex, sex with someone met online) and substance abuse (40, 44, 47, 52). Further, discussing drinking, drugs, and sex on social networks with street-based ties was linked to an increase in risky health behaviors, in comparison to discussions of love or goals/future plans $(47,52)$.

\section{DISCUSSION}

\section{Key Findings in Relation to Access and Use of ICTs}

The aims of our scoping review were to examine the ways that YEH access and use ICTs (i.e., frequency of use, purpose of use, barriers faced), and to discuss the implications of the findings for health care. We identified 16 studies (19 articles) demonstrating that there is a growing pool of evidence on access and use of ICTs among YEH, and that the use of ICTs plays an important role in their lives. At the same time, 16 studies of varying research design and sample sizes obtained through methods subject to sampling bias indicates an ongoing need for research on a highly marginalized population in urgent need for health care services (31).

In terms of our research questions, our key findings are: first, studies report high percentages of access to and use of ICTs
TABLE 2 | YEH's reasons for using ICTs.

\begin{tabular}{|c|c|}
\hline Reason for using ICTs & No of Studies \\
\hline $\begin{array}{l}\text { Navigating social networking sites (e.g., Facebook, Twitter, } \\
\text { MySpace, etc.) }(32,37,42-52)\end{array}$ & 13 \\
\hline $\begin{array}{l}\text { Communicating with peers (e.g., through email, social media, } \\
\text { instant messaging, text message, etc.) }(39,40,42-44,47-52)\end{array}$ & 11 \\
\hline $\begin{array}{l}\text { Communicating with family members (e.g., through email, } \\
\text { social media, instant messaging, text message, etc.) } \\
(39,40,42-44,47-49,51)\end{array}$ & 9 \\
\hline $\begin{array}{l}\text { Job related activities (e.g., job searching, resume building, } \\
\text { etc.) }(37,41-43,45,46,48,49,51)\end{array}$ & 9 \\
\hline $\begin{array}{l}\text { General communication/checking email (person they are } \\
\text { communicating with not specified) }(37-39,42,43,45,46,49)\end{array}$ & 8 \\
\hline $\begin{array}{l}\text { Seeking health services (e.g., searching for a doctor or health } \\
\text { clinic) }(40,41,45,46,53)\end{array}$ & 5 \\
\hline $\begin{array}{l}\text { Seeking general health-related information (e.g., looking up } \\
\text { mental health concerns and symptoms) }(40,41,45,46,53)\end{array}$ & 5 \\
\hline $\begin{array}{l}\text { Entertainment- and leisure-related activities (e.g., listening to } \\
\text { music, playing games, watching movies, etc.) } \\
(37,42,43,46,49)\end{array}$ & 5 \\
\hline $\begin{array}{l}\text { Education-related activities (e.g., navigating a school's } \\
\text { website or online portal, homework) }(37,43,46,48)\end{array}$ & 4 \\
\hline $\begin{array}{l}\text { Finding a place to stay (e.g., searching for apartment listings, } \\
\text { shelters, etc.) }(41,42,46,49)\end{array}$ & 4 \\
\hline $\begin{array}{l}\text { Dating/relationships (e.g., seeking a sexual partner online, } \\
\text { navigating a dating site, etc.) }(44,47,48,52)\end{array}$ & 4 \\
\hline $\begin{array}{l}\text { Communicating with case workers (e.g., through email, social } \\
\text { media, instant messaging, text message, etc.) }(39,47,49,51)\end{array}$ & 4 \\
\hline $\begin{array}{l}\text { Seeking sexual health-related information (e.g., information } \\
\text { about HIV prevention) }(40,45,46)\end{array}$ & 3 \\
\hline Seeking general information (e.g., using Google) $(37,42)$ & 2 \\
\hline $\begin{array}{l}\text { Practical uses (e.g., using a phone as an alarm clock or for } \\
\text { navigation) (37) }\end{array}$ & 1 \\
\hline
\end{tabular}

YEH, Youth experiencing homelessness; ICT, Internet communication technology; HIV, Human immunodeficiency virus.

by YEH (i.e., on average, across studies, $62.6 \%$ owned a mobile phone, with $68.8 \%$ owning a smartphone; $38.2 \%$ accessed the internet daily, with $55.1 \%$ reporting weekly access; and $77.1 \%$ used social media platforms). In comparison, surveys conducted with housed youth aged 13-17 in the USA and with youth aged 15-24 in Canada found that $92-96 \%$ of their samples went online daily, with nearly $75 \%$ of youth in the American sample reporting smartphone access $(55,56)$. The higher rates of ICT access in housed youth are unsurprising, considering that homelessness was linked to a decrease in internet use and access $(32,39,41,45$, 46). However, it is important to note that the studies we reviewed are subject to sampling bias (i.e., recruitment from shelters, drop ins), and thus should be interpreted with caution. Moreover, accessibility to ICTs may differ depending on the country (e.g., prices of technology, public resources, governmental programs, etc.) and across regional areas (e.g., provinces, states, cities).

$\mathrm{YEH}$ diverge from youth in the general population in the methods and barriers to accessing ICTs. Many YEH rely on public computers in libraries and community agencies to access the Internet, which is accompanied by a diverse range of obstacles 
(e.g., wait lists, restrictions on site searches). Owning a cell phone also represents a financial burden for many YEH, who may need to panhandle or share the device with a friend to afford it, which can lead to its deactivation $(38,39,43)$. These barriers can create a discontinuity in the sustainment of various social contacts for $\mathrm{YEH}$ and in the implementation of ICTs-based intervention.

Second, in the one study that discussed technology literacy, YEH reported confidence with their ICTs skills, due in part to exposure to technology at a young age (42). We also found that YEH used ICTs for an array of purposes, suggesting that they may be comfortable navigating and engaging with ICTsenabled health interventions. However, given that few studies have addressed technology literacy in this population, and that research with other young populations shows that youth encounter several challenges in searching the internet for healthrelated information (57), this topic warrants further attention.

Third, our findings show that technology supported the maintenance of positive and healthy social contacts, which was associated with less depressive symptoms, a reduction in substance-using behaviors and more adequate sexual health behaviors $(40,44,50,51)$. This suggests that high accessibility to ICTs could also allow YEH to maintain good social relationships, influencing health outcomes. However, it should be noted that using ICTs to connect with street-based peers and to discuss drinking, drugs, and sex increased the likelihood of engaging in these risky health behaviors $(44,47,51,52)$. Thus, it is important to be cognizant of the nature of YEH's online connections, and encourage the use of ICTs to maintain positive social contacts.

\section{Implications for Practice}

The use of technology-enabled interventions with homeless populations is a new area of research and practice for healthcare professionals with several elements to consider, including: increasing access to technology, optimizing technology-based infrastructure, providing training for community outreach and health workers, and engaging service users in the development of diverse and contextually-sensitive interventions (58).

The high rates at which YEH are accessing and using ICTs for various goal-oriented behaviors indicates that technology plays a critical role in their lives. Prioritizing free and accessible technology in public settings (e.g., shelters, community centers, libraries, harm reduction centers) and free access to mobile devices, may be an important way to empower $\mathrm{YEH}$, enable them to maintain connections with pro-social peers and family, and help build their awareness of public health guidelines, health services, and information.

Our findings support the notion that ICTs can improve communication with YEH for outreach purposes (31). Considering that YEH access and use a variety of ICTs, health care providers may consider ICT-based forms of communication to provide services and information. Concurrently, diversity in communicating with and disseminating information to $\mathrm{YEH}$ (i.e., using both online and offline methods) is an important factor to consider, given that not all YEH have regular access and use of technology, which may be further exacerbated during public health crises requiring physical distancing.

\section{Study Limitations}

This scoping review has several limitations. We did not systematically assess the quality of studies given the heterogeneity of study methods, nor did we conduct a gray literature search. Similarly, due to time and human resources, only English language publications were included. It is therefore possible that some studies were omitted by the search strategy. In addition, as there was inconsistency in the ways in which papers reported their sociodemographic information and findings (e.g., eight papers reported on daily internet use, but only four of those papers additionally reported on weekly internet use), the weighted means reported in this review may not apply to the entirety of the study sample. Finally, as the present study is not a formal meta-analysis, we did not use more complex statistical pooling methods or analyze the heterogeneity in our data; as such, our results should be interpreted with these considerations in mind.

\section{Future Research}

This scoping review highlights several research gaps, upon which we base the following recommendations: (1) international research is needed to understand YEH's access and use of ICTs, and to explore the impacts of varying infrastructures, government policies, and socioeconomic factors on YEH's experiences with technology; (2) more effort is needed to capture representative samples of the $\mathrm{YEH}$ population, characterizing the samples in terms of sociodemographic factors, and the role that these factors may play in their access and use of technology; (3) more consistency is needed in how access and use of technology is assessed and reported, as this will help to better synthesize the literature moving forward; (4) more research is needed on the digital health literacy skills of this population and their experiences of using technology to search for, and access health-related information and services; (5) quality appraisal will be an increasingly important consideration as more research emerges on access and use of ICTs among YEH; (6) more research is needed on how COVID-related public health guidelines affect access to publicly available ICTs (e.g., through libraries) and may further marginalize YEH from accessing critical health information and services; (7) future research should also focus on developing and evaluating technology-enabled health interventions for YEH. Indeed, we found that there is an emerging body of literature on the use of technology to deliver health related services to the homeless population, including youth. This is an important avenue to consider for a future review, to better examine the feasibility, acceptability, and efficacy of providing health services to $\mathrm{YEH}$ through this method of service delivery.

\section{CONCLUSION}

Our findings indicate that YEH access and use ICTs for many purposes, and they appear to have the foundational skills, interests, and needs to engage with such types of technologies for health purposes. However, barriers to access need to be considered. More research is needed on the 
appropriate and effective way of leveraging ICTs for public health and health related interventions tailored for $\mathrm{YEH}$. Given the urgency of YEH's health care needs and their marginalization from health care systems, it is important to pursue research on the impact of these technologies on YEH and health information and services for this vulnerable population.

\section{DATA AVAILABILITY STATEMENT}

The original studies presented in this review are included in the article/Supplementary Material, further inquiries can be directed to the corresponding author/s.

\section{AUTHOR CONTRIBUTIONS}

SL conceived the original idea for this scoping review, its overall methodology, and supervision of its implementation. SL and AF contributed to writing the initial protocol. SL and AH-A contributed to its revisions and finalization. SL prepared the initial draft of the manuscript, with contributions from $\mathrm{AH}-\mathrm{A}$. All authors contributed substantially to the content and approved the final version.

\section{REFERENCES}

1. Aratani Y. Homeless Children and Youth: Causes and Consequences. New York, NY: National Center for Children in Poverty (2009). p. 14.

2. Gaetz SA, O'Grady B, Kidd S, Schwan K. Without a Home: The National Youth Homelessness Survey. Toronto, ON: Canadian Observatory on Homelessness Press (2016). p. 126.

3. Gaetz S, O'Grady B, Buccieri K, Marsolais A. Youth Homelessness in Canada: Implications for Policy and Practice. Toronto, ON: Canadian Homelessness Research Network (2013).

4. Clarke A, Burgess G, Morris S, Udagawa C. Estimating the Scale of Youth Homelessness in the UK. Cambridge: Cambridge Centre for Housing \& Planning Research (2015). p. 54.

5. Evenson J. Youth Homelessness in Canada: The Road to Solutions. Toronto, ON: Raising the Roof (2009). p. 44.

6. Latimer E, McGregor J, Méthot C, Smith A. I Count MTL 2015: Count and Survey of Montreal's Homeless Population on March 24, 2015. Montreal, QC: Douglas Mental Health University Institute (2015). p. 81.

7. Dworsky A. The prevalence of youth homelessness in the United States. In: Warf C, Charles G, editors. Clinical Care for Homeless, Runaway and Refugee Youth: Intervention Approaches, Education and Research Directions. New York, NY: Springer International Publishing (2020). p. $1-10$.

8. Morton MH, Dworsky A, Samuels GM. Missed Opportunities: Youth Homelessness in America. National Estimates. Chicago, IL: The University of Chicago (2017). p. 16.

9. Charles G, Warf C, Tennant G. Youth homelessness in Canada: an overview. In: Warf C, Charles G, editors. Clinical Care for Homeless, Runaway and Refugee Youth: Intervention Approaches, Education and Research Directions. 1st ed. New York, NY: Springer International Publishing (2020). p. 11-8.

10. Segaert A. The National Shelter Study: Emergency Shelter Use in Canada. Ottawa, ON: Employment and Social Development Canada (2012). p. 45.

11. Kidd SA, Gaetz S, O'Grady B. The 2015 National Canadian homeless youth survey: mental health and addiction findings. Can J Psychiatry. (2017) 62:493500. doi: $10.1177 / 0706743717702076$

\section{FUNDING}

SL is supported by a Canada Research Chair in Innovation and Technology for Youth Mental Health Services, and previously through a New Investigator Salary Award from the Canadian Institutes of Health Research.

\section{ACKNOWLEDGMENTS}

Preliminary findings have been presented at the 9th Annual eMental Health Conference in Toronto, Canada and at the annual 20th WPA World Congress of Psychiatry. We would also like to thank Kawtar Zitour for contributing to the validation of data extraction pertaining to a subset of the studies reviewed and Myrian Grondin for assisting with the development and implementation of the search strategy.

\section{SUPPLEMENTARY MATERIAL}

The Supplementary Material for this article can be found online at: https://www.frontiersin.org/articles/10.3389/fdgth. 2021.782145/full\#supplementary-material

12. Kulik DM, Gaetz S, Crowe C, Ford-Jones E. Homeless youth's overwhelming health burden: a review of the literature. Pediatr Child Health. (2011) 16:e437. doi: $10.1093 / \mathrm{pch} / 16.6 . \mathrm{e} 43$

13. Baakeel OA. Homeless teenagers: the growing segment of homelessness in the US. J Educ Soc Behav Sci. (2014) 2014:857-68. doi: 10.9734/BJESBS/20 $14 / 7234$

14. Aviles AM, Helfrich CA. Homeless youth: causes, consequences and the role of occupational therapy. Occup Ther Health Care. (2006) 20:99114. doi: 10.1300/J003v20n03_07

15. Busen NH, Engebretson JC. Facilitating risk reduction among homeless and street-involved youth. J Am Acad Nurse Pract. (2008) 20:5675. doi: 10.1111/j.1745-7599.2008.00358.x

16. Elliott AS, Canadian Paediatric Society, Adolescent Health Committee. Meeting the health care needs of street-involved youth. Paediatr Child Health. (2013) 18:317-21. doi: 10.1093/pch/18.6.317

17. Ferguson KM, Bender K, Thompson SJ. Predicting illegal income generation among homeless male and female young adults: understanding strains and responses to strains. Child Youth Serv Rev. (2016) 63:101-9. doi: 10.1016/j.childyouth.2016.02.016

18. Hughes JR, Clark SE, Wood W, Cakmak S, Cox A, MacInnis M, et al. Youth homelessness: the relationships among mental health, hope, and service satisfaction. J Can Acad Child Adolesc Psychiatry. (2010) 19:274.

19. O’Brien JRG, Edinburgh LD, Barnes AJ, McRee A-L. Mental health outcomes among homeless, runaway, and stably housed youth. Pediatrics. (2020) 145:e20192674. doi: 10.1542/peds.2019-2674

20. Black EB, Fedyszyn IE, Mildred H, Perkin R, Lough R, Brann P, et al. Homeless youth: Barriers and facilitators for service referrals. Eval Program Plann. (2018) 68:7-12. doi: 10.1016/j.evalprogplan.2018.02.009

21. Edidin JP, Ganim Z, Hunter SJ, Karnik NS. The mental and physical health of homeless youth: a literature review. Child Psychiatry Hum Dev. (2012) 43:354-75. doi: 10.1007/s10578-011-0270-1

22. Solorio MR, Milburn NG, Andersen RM, Trifskin S, Rodríguez MA. Emotional distress and mental health service use among urban homeless adolescents. J Behav Health Serv Res. (2006) 33:381-93. doi: 10.1007/s11414-006-9037-z 
23. Pedersen ER, Tucker JS, Kovalchik SA. Facilitators and barriers of dropin center use among homeless youth. J Adolesc Health. (2016) 59:14453. doi: 10.1016/j.jadohealth.2016.03.035

24. Auerswald CL, Lin JS, Parriott A. Six-year mortality in a street-recruited cohort of homeless youth in San Francisco, California. PeerJ. (2016) 4:e1909. doi: 10.7717/peerj.1909

25. Boivin J-F, Roy É, Haley N, du Fort GG. The health of street youth. Can J Public Health. (2005) 96:432-7. doi: 10.1007/BF03405183

26. Davies A, Wood LJ. Homeless health care: meeting the challenges of providing primary care. Med J Aust. (2018) 209:230-4. doi: 10.5694/mja17.01264

27. Hwang SW. Mortality among men using homeless shelters in Toronto, Ontario. JAMA. (2000) 283:2152-7. doi: 10.1001/jama.283.16.2152

28. Perry J, Craig TKJ. Homelessness and mental health. Trends Urol Men Health. (2015) 6:19-21. doi: 10.1002/tre.445

29. Romaszko J, Cymes I, Dragańska E, Kuchta R, Glińska-Lewczuk K. Mortality among the homeless: causes and meteorological relationships. PLOS ONE. (2017) 12:e0189938. doi: 10.1371/journal.pone.0189938

30. Roy É, Haley N, Leclerc P, Sochanski B, Boudreau J-F, Boivin J-F. Mortality in a cohort of street youth in Montreal. JAMA. (2004) 292:56974. doi: 10.1001/jama.292.5.569

31. McInnes DK, Li AE, Hogan TP. Opportunities for engaging low-income, vulnerable populations in health care: a systematic review of homeless persons' access to and use of information technologies. Am J Public Health. (2013) 103:e11-24. doi: 10.2105/AJPH.2013.301623

32. Harpin S, Davis J, Low H, Gilroy C. Mobile phone and social media use of homeless youth in Denver, Colorado. J Community Health Nurs. (2016) 33:90-7. doi: 10.1080/07370016.2016.1159440

33. Arksey H, O'Malley L. Scoping studies: towards a methodological framework. Int J Soc Res Methodol. (2005) 8:19-32. doi: 10.1080/1364557032000119616

34. Lal S, Jarus T, Suto MJ. A scoping review of the photovoice method: implications for occupational therapy research. Can J Occup Ther. (2012) 79:181-90. doi: 10.2182/cjot.2012.79.3.8

35. Tricco AC, Lillie E, Zarin W, Perkin R, Lough R, Brann P, et al. A scoping review on the conduct and reporting of scoping reviews. BMC Med Res Methodol. (2016) 16:15. doi: 10.1186/s12874-016-0116-4

36. Tricco AC, Lillie E, Zarin W, O’Brien KK, Colquhoun H, Levac D, et al. PRISMA extension for scoping reviews (PRISMA-ScR): Checklist and explanation. Ann Intern Med. (2018) 169:467-73. doi: 10.7326/M18-0850

37. Adkins EC, Zalta AK, Boley RA, Glover A, Karnik NS, Schueller SM. Exploring the potential of technology-based mental health services for homeless youth: a qualitative study. Psychol Serv. (2017) 14:238. doi: $10.1037 /$ ser0000120

38. Jennings L, Lee N, Shore D, Strohminger N, Allison B, Conserve DF, et al. US minority homeless youth's access to and use of mobile phones: Implications for mHealth intervention design. J Health Commun. (2016) 21:725-33. doi: 10.1080/10810730.2015.1103331

39. Rice E, Lee A, Taitt S. Cell phone use among homeless youth: potential for new health interventions and research. J Urban Health. (2011) 88:117582. doi: 10.1007/s11524-011-9624-z

40. Barman-Adhikari A, Rice E. Sexual health information seeking online among runaway and homeless youth. J Soc Social Work Res. (2011) 2:89103. doi: 10.5243 /jsswr.2011.5

41. Curry SR, Rhoades H, Rice E. Correlates of homeless youths' stabilityseeking behaviors online and in person. J Soc Social Work Res. (2016) 7:14376. doi: 10.1086/685107

42. Karabanow J, Naylor TD. Being hooked up: exploring the experiences of street youth and information technologies. In: Looker ED, Naylor TD, editors. Digital Diversity: Youth, Equity, and Information Technology. Waterloo, ON: Wilfrid Laurier University Press (2010). p. 161-78.

43. Pollio DE, Batey DS, Bender K, Ferguson K, Thompson S. Technology use among emerging adult homeless in two U.S. Cities. Soc Work. (2013) 58:173-5. doi: 10.1093/sw/swt006

44. Rice E, Monro W, Barman-Adhikari A, Young SD. Internet use, social networking, and HIV/AIDS risk for homeless adolescents. J Adolesc Health. (2010) 47:610-3. doi: 10.1016/j.jadohealth.2010.04.016

45. VonHoltz LAH, Frasso R, Lu Y, Hanlon AL, Dowshen NL. 105. new media use and health information-seeking behavior among homeless adolescents. J Adolesc Health. (2015) 56:S55. doi: 10.1016/j.jadohealth.2014. 10.111

46. VonHoltz LAH, Frasso R, Golinkoff JM, Lozano AJ, Hanlon A, Dowshen N. Internet and social media access among youth experiencing homelessness: mixed-methods study. J Med Internet Res. (2018) 20:e184. doi: 10.2196/jmir.9306

47. Barman-Adhikari A, Rice E, Bender K, Lengnick-Hall R, Yoshioka-Maxwell A, Rhoades H. Social networking technology use and engagement in HIVrelated risk and protective behaviors among homeless youth. J Health Commun. (2016) 21:809-17. doi: 10.1080/10810730.2016.1177139

48. Guadagno RE, Muscanell NL, Pollio DE. The homeless use Facebook?! Similarities of social network use between college students and homeless young adults. Comput Human Behav. (2013) 29:86-9. doi: 10.1016/j.chb.2012.07.019

49. Rice E, Barman-Adhikari A. Internet and social media use as a resource among homeless youth. J Comput Mediat Commun. (2014) 19:23247. doi: $10.1111 /$ jcc4.12038

50. Rice E, Kurzban S, Ray D. Homeless but connected: the role of heterogeneous social network ties and social networking technology in the mental health outcomes of street-living adolescents. Community Ment Health J. (2012) 48:692-8. doi: 10.1007/s10597-011-9462-1

51. Rice E, Milburn NG, Monro W. Social networking technology, social network composition, and reductions in substance use among homeless adolescents. Prev Sci. (2011) 12:80-8. doi: 10.1007/s11121-010-0191-4

52. Young SD, Rice E. Online social networking technologies, HIV knowledge, and sexual risk and testing behaviors among homeless youth. AIDS Behav. (2011) 15:253-60. doi: 10.1007/s10461-010-9810-0

53. Robards F, Kang M, Usherwood T, Jan S, Kong M, Steinbeck K, et al. How do marginalized young people navigate the Australian healthcare system? J Adolesc Health. (2018) 62 (2 Supplement 1):S1123. doi: 10.1016/j.jadohealth.2017.11.229

54. Hendry DG, Woelfer JP, Duong T. U-District Job Co-op: constructing a future vision for homeless young people and employment. Inf Technol People. (2017) 30:602-28. doi: 10.1108/ITP-05-2015-0117

55. Lenhart A. Teens, Social Media and Technology Overview 2015. Washington, DC: Pew Research Center (2015). p. 48.

56. Statistics Canada. General Social Survey: Canadians at Work and Home (GSS). Ottawa, ON: Statistics Canada (2017).

57. Lal S, Nguyen V, Theriault J. Seeking mental health information and support online: experiences and perspectives of young people receiving treatment for first-episode psychosis. Early Interv Psychiatry. (2018) 12:32430. doi: 10.1111/eip.12317

58. Lal S. E-mental health: promising advancements in policy, research, and practice. Healthc Manage Forum. (2019) 32:5662. doi: $10.1177 / 0840470418818583$

Conflict of Interest: SL has received an investigator-initiated, digital health operational research grant from Hoffman-La Roche, unrelated to this study.

The remaining authors declare that the research was conducted in the absence of any commercial or financial relationships that could be construed as a potential conflict of interest.

Publisher's Note: All claims expressed in this article are solely those of the authors and do not necessarily represent those of their affiliated organizations, or those of the publisher, the editors and the reviewers. Any product that may be evaluated in this article, or claim that may be made by its manufacturer, is not guaranteed or endorsed by the publisher.

Copyright (C) 2021 Lal, Halicki-Asakawa and Fauvelle. This is an open-access article distributed under the terms of the Creative Commons Attribution License (CC BY). The use, distribution or reproduction in other forums is permitted, provided the original author(s) and the copyright owner(s) are credited and that the original publication in this journal is cited, in accordance with accepted academic practice. No use, distribution or reproduction is permitted which does not comply with these terms. 